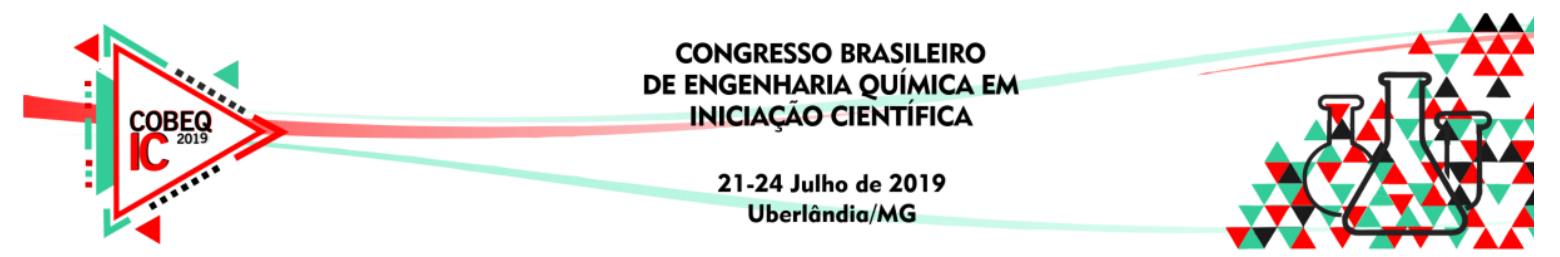

\title{
CARACTERIZAÇÃO QUÍMICA DOS COMPOSTOS EXTRAÍDOS DA SEMENTE DE ABÓBORA CABOTIA (Cucurbita maxima $x$ Cucurbita moschata) OBTIDO POR DIFERENTES MÉTODOS DE EXTRAÇÃO
}

\author{
G. J. R. SOUZA, I. O. RODRIGUES, P. S. CAMPOS, C. I. SILVA e G.C. R. SILVA \\ Universidade Federal de São João del Rei, Laboratório de Engenharia de Processos e \\ Tecnologia \\ grazielejrsouza@gmail.com
}

\begin{abstract}
RESUMO - O presente estudo avaliou e caracterizou os compostos extraídos das sementes de abóbora por diferentes metodologias, com a intenção de propor uma utilização mais nobre deste resíduo. Foram utilizados dois diferentes métodos para a extração dos óleos, prensagem mecânica e extração por Soxhlet. Primeiramente, as sementes de abóbora eram secas em estufa a vácuo a $110^{\circ} \mathrm{C}$ até peso constante e em seguida, eram trituradas em um processador. $O$ processo de extração por Soxhlet, utilizou hexano como solvente e a prensagem mecânica foi realizada em uma prensa manual. Após as extrações, os extratos oleaginosos foram submetidos a análises de índice de acidez, compostos fenólicos, carotenoides, vitamina $\mathrm{C}$, índice de iodo e, além disso, obteve-se o rendimento das extrações. A técnica de prensagem foi a que produziu o menor rendimento em óleo bruto. Os métodos propostos mostraram ser eficientes e capazes de extrair um óleo de qualidade para a utilização comercial, agregando valor a este resíduo da indústria alimentícia.
\end{abstract}

\section{INTRODUÇÃO}

A abóbora cabotia, também conhecida abóbora japonesa, é resultante do cruzamento entre linhagens de moranga (Cucurbita maxima Duch.) e linhagens de abóbora (C. moschata Duch. et Poir.), segundo Amarante et al (1994) e Bisognin (2002).

Em algumas regiões carentes, a semente de abóbora cabotia é consumida como complemento alimentar, por conter vitaminas e carboidratos. Estudos de Veronezi e Jorge (2012) mostraram que as sementes de abóbora têm em média 32 a 40\% de óleo, sendo ricas em ácidos graxos mono e poli-insaturados, vitaminas $\mathrm{E}$ (tocoferol), vitaminas $\mathrm{C}$ (ácido ascórbico) e elevado teor proteico, além de possuir baixos teores de açúcares livres de amido, grandes quantidades de minerais, como magnésio, potássio, fósforo e ferro.

Inicialmente a extração de óleos vegetais era efetuada por método físico, através do uso de prensas. Porém, desde as primeiras décadas deste século, a extração de óleos vegetais por solventes mostrou-se bem mais interessante, sendo o hexano o solvente mais utilizado, conforme em trabalho publicado por O'Brien (2004). Entretanto, esta técnica tem como desvantagem utilizar uma fonte de matéria-prima não renovável, tóxica e inflamável, além de poder causar perdas de componentes importantes a qualidade do produto final. Portanto, é de 


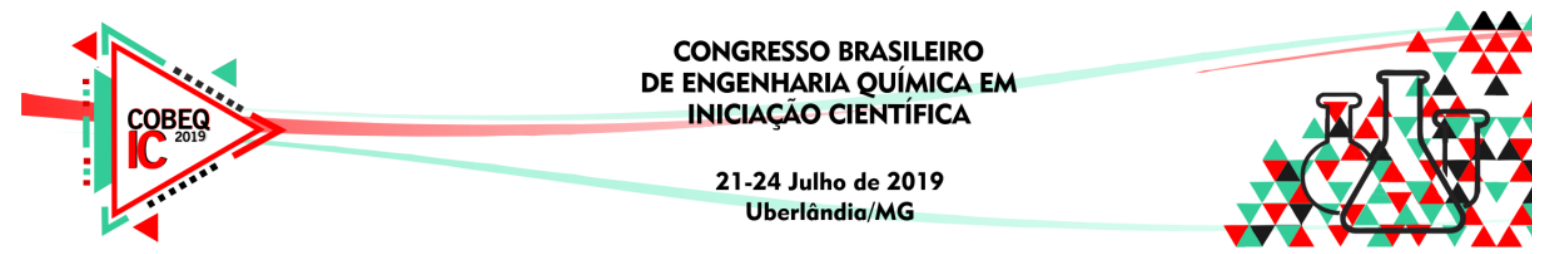

grande importância a caracterização química dos extratos oleaginosos obtidos por diferentes metodologias, a fim de identificar o produto de melhor qualidade para ser empregado em indústrias de alimentos, cosméticos e/ou farmacêuticas.

\section{METODOLOGIA EXPERIMENTAL}

\subsection{Obtenção da Amostra}

O trabalho foi realizado no Laboratório de Engenharia de Processos e Tecnologias (LENGTEC/UFSJ/CCO) em Divinópolis-MG. As sementes de abóbora cabotia foram obtidas no comércio local de Divinópolis - MG. As sementes foram secas em estufa a vácuo, por 24 horas com uma temperatura de $110^{\circ} \mathrm{C}$ até obtenção de peso constante. Em seguida, foram trituradas em processador, obtendo uma farinha. A farinha foi estocada em sacos plásticos, e armazenada em temperatura de $-18^{\circ} \mathrm{C}$ em um freezer. Todas as análises foram realizadas em triplicata.

\subsection{Métodos de Extração}

Extração por Soxhlet: Foi realizada conforme descrito em AOCS (2004), com o solvente hexano a $70^{\circ} \mathrm{C}$ por 8 horas. A proporção amostra-solvente utilizada foi de 1:30. Os extratos obtidos foram, posteriormente, submetidos ao processo de eliminação do solvente em evaporador rotativo.

Extração mecânica: Foi realizada em uma prensa mecânica, que é constituída por um pistão, acionado manualmente, que comprime o material contido no cesto em aço inoxidável provido de orifícios de saída para o líquido prensado, em ciclos de tempo e pressões definidas. Esta prensa tem capacidade de $100 \mathrm{~g}$ por batelada.

Como a eficiência das prensas manuais é influenciada diretamente pelo pré-tratamento a que a matéria-prima é submetida, avaliou-se três formas de alimentação das sementes de abóbora. A primeira utilizou-se sementes de abóboras inteiras e aquecidas a uma temperatura de $50^{\circ} \mathrm{C}$ (ao longo do trabalho recebe o nome de $\mathrm{EPM}_{1}$ ). A segunda, sementes inteiras a temperatura ambiente $\left(\mathrm{EPM}_{2}\right)$. Já a terceira, as sementes foram trituradas e aquecidas em uma temperatura de $50^{\circ} \mathrm{C}\left(\mathrm{EPM}_{3}\right)$

Os extratos oleaginosos coletados foram pesados e transferidos para um tubo falcon de $15 \mathrm{~mL}$ e levados à centrífuga a $3000 \mathrm{rpm}$ durante 10 minutos. Esse procedimento foi repetido até obtenção de um óleo limpo sem presença de impurezas sólidas. Posteriormente, os óleos foram passados para pequenos frascos de vidro tampados, devidamente etiquetados, pesados e envoltos com papel alumínio. Estes frascos foram armazenados em um local seco, seguro e escuro até a realização das análises.

\section{ANÁLISES DOS EXTRATOS}

Rendimento global: $\mathrm{O}$ rendimento global da extração foi calculado pela diferença entre a massa das sementes de abóbora antes e após as extrações, expresso em percentagem, utilizando a Equação 1. 


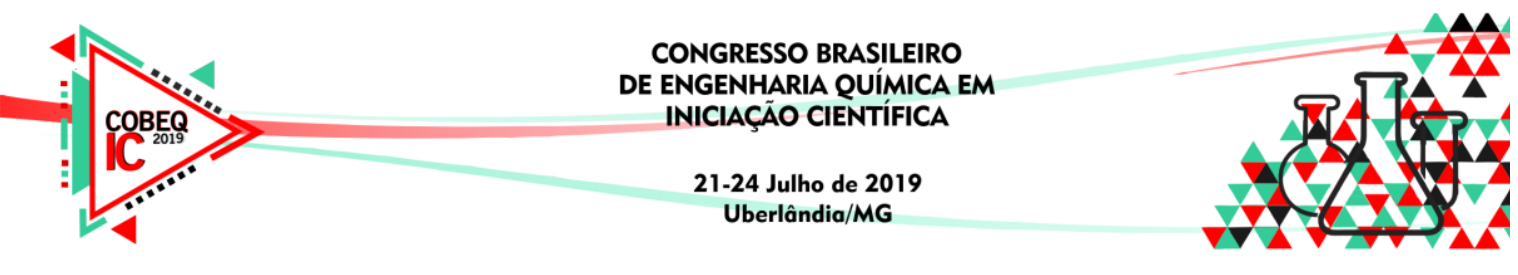

$$
R(\%)=\frac{P_{1}-P_{2}}{P_{1}}
$$

Sendo, $\mathrm{P}_{1}$ o peso inicial da amostra de sementes de abóbora, $\mathrm{P}_{2}$ o peso final da amostra após a extração.

Índice de Acidez: foi determinado segundo o método AOCS (2004), em que se pesava aproximadamente $0,5 \mathrm{~g}$ de óleo em um erlenmeyer, em seguida adicionava-se $25 \mathrm{~mL}$ de álcool etílico $95 \%$ e 4 gotas de fenolftaleína 1\%. A amostra era então titulada com hidróxido de sódio $0,1 \mathrm{~N}$ até o aparecimento da cor rósea, relativo ao ponto de viragem. Para os cálculos do índice de acidez, expresso em \% de ácidos graxos livres (AGL), foi utilizado a Equação 2.

$$
\text { Índice de acidez }=\frac{\text { volume gasto de } N A O H \times 0,1 N \times 28,2}{\text { Massa de amostra }(g)}
$$

Sendo, que o valor de 28, 2 na Equação 2 representa o índice resultante da amostra padrão de ácido oleico.

Índice de Iodo: o método consistiu em adicionar $0,15 \mathrm{~g}$ do óleo extraído das sementes de abóbora em $10 \mathrm{~mL}$ de clorofórmio e $12,5 \mathrm{~mL}$ do sal de Wijs, em um erlenmeyer de $250 \mathrm{~mL}$, devidamente envolvido por papel alumínio. Este ficava em repouso por 30 minutos dentro da capela em temperatura ambiente. Posteriormente, adicionava-se na solução $10 \mathrm{~mL}$ de iodeto de potássio a $20 \%$ e $50 \mathrm{~mL}$ de água deionizada. A titulação era realizada com tiossulfato de sódio $0,1 \mathrm{~N}$ até o ponto de viragem de amarelo claro. Assim, quando essa coloração era obtida, adicionava-se $2 \mathrm{~mL}$ da solução de amido que fazia com que a solução ficasse mais escura. Então, uma nova titulação era iniciada até obter o ponto de viragem branco leitoso.

Compostos fenólicos totais: Para determinar a quantidade de polifenóis totais em todos os extratos foi utilizado o método espectrofotométrico do reagente Folin-Ciocalteau, descrito por Singleto et al. (1999) com modificações. O método consiste em adicionar 0,0142g do óleo da semente de abóbora em tubo de ensaio e adicionar $5 \mathrm{~mL}$ de metanol, homogeneizar e aguardar 5 minutos. Após os 5 minutos retirava-se $88 \mu \mathrm{L}$ da amostra e adicionava-se $912 \mu \mathrm{L}$ de metanol. Os tubos eram levados para a capela e, com auxílio de uma manta aquecedora reduzia o fluxo em 50\% do volume. Ao atingir essa redução, os tubos eram retirados da capela e deixados a esfriar em temperatura ambiente. Em seguida, adiciona-se $2,5 \mathrm{~mL}$ de folin a $10 \%$ e $20 \mathrm{~mL}$ de carbonato de sódio a 7,5\% no tubo de ensaio que era homogeneizado e colocados em banho maria por 5 minutos a $50^{\circ} \mathrm{C}$. O branco era preparado em outro tubo e seguia a mesma metodologia dos tubos com amostra de óleo de semente de abóbora. A absorção das amostras era, então, lida em um espectrofotômetro em um comprimento de onda de $765 \mathrm{~nm}$. Os resultados foram obtidos em mg de ácido gálico/g de óleo, de acordo com a Equação 3.

$$
\text { Compostos fenolicos totais }(m g A G / g \text { de óleo })=\frac{(\text { Absorbância }+B)}{(A \times g \text { de óleo })}
$$

Sendo que, os valores referentes a A e B na Equação 3 foram obtidos pela a curva padrão de concentração de ácido gálico por absorbância $(y=A x+B)$, sendo $y$ a absorbância e $x$ mg de 


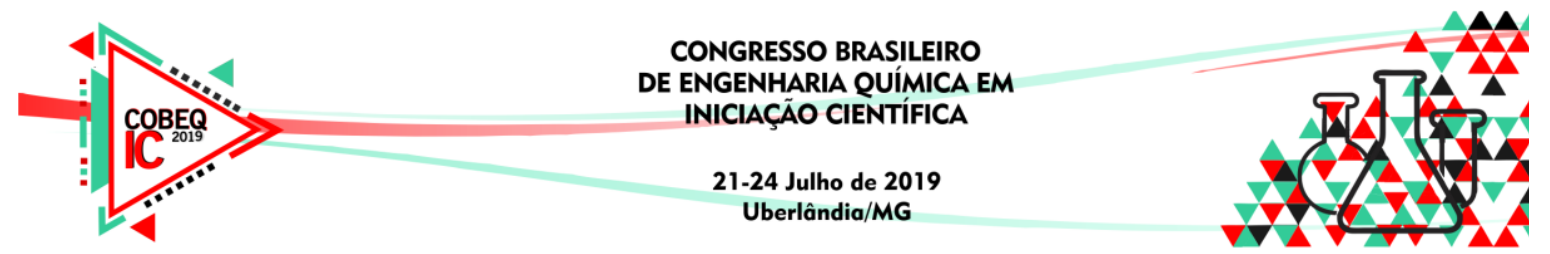

ácido gálico/mL.

Carotenoides: A determinação de carotenoides foi realizada segundo método proposto por Higby et al. (1962). Para os cálculos do teor de carotenoides totais foi utilizada a Equação 4.

Carotenóides $(m g / 100 g)=\frac{\text { Volume final } \times \text { Absorbância } \times 100}{\text { Peso da amostra } \times 2500}$

Vitamina C: O teor de vitamina C foi determinado segundo Strohecker e Henning (1967). Para os cálculos do teor de vitamina $\mathrm{C}$ foi utilizada a Equação 5.

Vitamina $C(m g / 100 g)=\frac{\text { Volume gasto na titulação } x \text { Fc } x 100}{\text { Peso da amostra }}$

Sendo Fc correspondente ao fator de correção, que foi definido como 1 e a multiplicação por 100 foi realizada para obter o valor em porcentagem.

\section{RESULTADO E DISCUSSÃO}

\subsection{Métodos de Extração}

Na Tabela 1, pode-se observar os rendimentos globais obtidos para a extração por Soxhlet (ESH) e prensagem mecânica com os diferentes tipos de alimentação, isto é, semente inteira e aquecida $\left(\mathrm{EPM}_{1}\right)$, semente inteira e sem aquecimento $\left(\mathrm{EPM}_{2}\right)$ e semente triturada com aquecimento $\left(\mathrm{EPM}_{3}\right)$.

Tabela 1- Rendimento das extrações

\begin{tabular}{cc}
\hline Tipo de Extração & Rendimento (\%) \\
\hline ESH & 54,55 \\
EPM $_{1}$ & 24,78 \\
EPM $_{2}$ & 25,75 \\
EPM $_{3}$ & 35,56 \\
\hline
\end{tabular}

A extração por Soxhlet com hexano apresentou melhor rendimento em massa (ESH), que pode ser explicado pelo solvente hexano possuir grande capacidade de arrastar o óleo durante a extração. $\mathrm{O}$ rendimento da $\mathrm{EPM}_{3}$ foi mais alto, se comparados com as outras extrações por prensagem mecânica, que pode ser explicado por ser utilizada semente triturada e aquecida, que tem maior superfície de contato e temperatura adequadas para a extração do óleo.

\subsection{Análises dos extratos}

A Tabela 2 demonstra os dados médios e desvio padrão encontrados para as análises químicas dos extratos obtidos das sementes de abóbora para as diferentes extrações. 


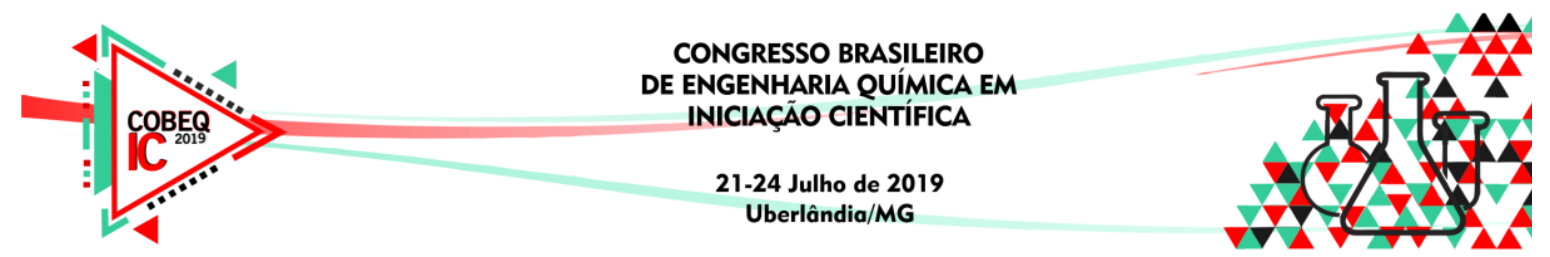

Tabela 2- Análises de caracterização físico-química para os diferentes tipos de extração das sementes de abóbora

\begin{tabular}{cccccc}
\hline Extrato & $\begin{array}{c}\text { Índice de } \\
\text { Acidez }(\% \mathbf{A G L})\end{array}$ & $\begin{array}{c}\text { Compostos } \\
\text { Fenólicos } \\
(\mathbf{m g ~ G A E} / \mathbf{m L})\end{array}$ & $\begin{array}{c}\text { Carotenoides } \\
(\mathbf{m g} / \mathbf{1 0 0 g})\end{array}$ & $\begin{array}{c}\text { Vitamina C } \\
(\mathbf{m g} / \mathbf{1 0 0 g})\end{array}$ & $\begin{array}{c}\text { Índice de } \\
\mathbf{I o d o} \\
(\mathbf{g I} / \mathbf{1 0 0 g})\end{array}$ \\
\hline $\mathrm{E}_{\mathrm{SH}}$ & $2,58 \pm 0,35$ & $0,417 \pm 0,09$ & $0,146 \pm 0,00$ & $83,30 \pm 5,77$ & $104,3 \pm 5,81$ \\
$\mathrm{E}_{\mathrm{PM} 1}$ & $3,85 \pm 1,11$ & $0,303 \pm 0,08$ & $0,184 \pm 0,01$ & $233,00 \pm 57,73$ & $121,8 \pm 1,90$ \\
$\mathrm{E}_{\mathrm{PM} 2}$ & $3,31 \pm 0,55$ & $0,328 \pm 0,02$ & $0,190 \pm 0,00$ & $116,00 \pm 28,86$ & $96,03 \pm 2,05$ \\
$\mathrm{E}_{\mathrm{PM} 3}$ & $2,56 \pm 0,31$ & $0,393 \pm 0,06$ & $0,199 \pm 0,00$ & $150,00 \pm 0,00$ & $105,0 \pm 3,51$ \\
\hline
\end{tabular}

O índice de acidez está relacionado com a natureza, grau de pureza, qualidade, processamento e condições de conservação do óleo vegetal, conforme estudo realizado por Machado et al. (2006). De acordo com os dados apresentados na Tabela 2, obtiveram-se valores médios de acidez abaixo de 4,0\%, sendo este valor é aceitável pela ANVISA conforme RDC 270 de 22 de setembro de 2005 (ANVISA, 2019). Sendo assim, os diferentes tipos de extração estudados geram óleos dentro do esperado para índice de acidez.

Segundo Maia (2006), quanto maior o índice de iodo, maior o número de duplas ligações (instaurações) presentes no óleo, sendo assim, há uma maior probabilidade da amostra ser considerada um óleo do que uma gordura. As extrações se mantiveram dentro do esperado (100 a $150 \mathrm{gI}_{2} / 100 \mathrm{~g}$ ), exceto a extração $\mathrm{EMP}_{2}$ que apresentou um índice de iodo de 96,03 g/2/100g. Isso mostra que o aquecimento das sementes anteriormente à extração pode causar alterações no óleo obtido.

A vitamina $\mathrm{C}$ é um poderoso antioxidante que auxilia na diminuição e na neutralização dos efeitos que os radicais livres produzem naturalmente no organismo humano causando diversos problemas estruturais, muitas vezes responsáveis pelo surgimento das chamadas doenças crônicas. O óleo de abóbora apresentou quantidades significativas de vitamina $\mathrm{C}$ nos dois tipos de extração estudados. A extração mecânica $\left(\mathrm{EPM}_{1}\right)$, utilizando as sementes inteiras e aquecidas, mostrou obter um óleo com elevado teor de vitamina C. Sendo, então, indicado para obtenção de produtos que se tenha interesse em alta concentração de ácido ascórbico.

\section{CONSIDERAÇÕES FINAIS}

A indústria alimentícia tem dado grande atenção aos subprodutos vegetais, após o crescimento na demanda por alimentos funcionais, que carregam importantes fatores nutricionais na sua composição e dentre eles pode-se destacar as sementes de abóbora por possuir alto teor de proteínas, minerais, vitaminas e gordura insaturada. Sendo assim, é importante estudos que avaliem e caracterizem os extratos obtidos das sementes de abóbora. Neste trabalho, a extração por soxhlet mostrou maior rendimento em óleo bruto $(54,55 \%$, em massa). As análises realizadas demonstraram que para o teor de carotenoides e vitamina $\mathrm{C}$, a prensagem mecânica apresentou melhores resultados. Ou seja, apresenta um extrato que pode 


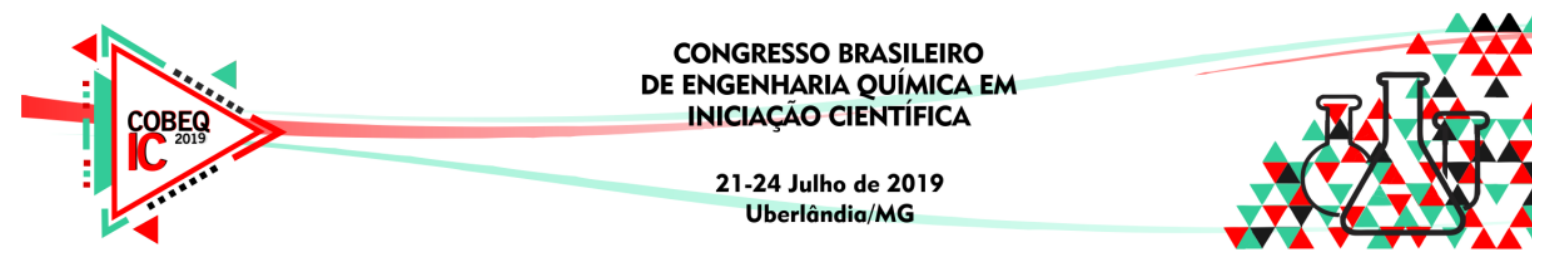

ser utilizado em produtos que se deseja a ação contra radicais livres. Identificou-se que o óleo das sementes de abóbora possui elevado teor proteico $(450 \mathrm{~g} / \mathrm{kg})$, possibilitando o seu uso na fortificação de alimentos e aumentando, assim, as concentrações proteicas de preparações alimentares. Portanto, os métodos propostos mostraram ser eficientes e capazes de extrair um óleo de qualidade para a utilização comercial. Sendo a prensagem mecânica o método que oferece um extrato com maiores características antioxidantes, que podem ser utilizados em produtos com efeitos preventivos para distúrbios fisiológicos e imunológicos.

\section{REFERÊNCIAS BIBLIOGRÁFICAS}

AMARANTE, C.V.T.; MACEDO, A.F.; ARRUDA, A.E. Controle de frutificação em abóbora híbrida 'Tetsukabuto'. Agropecuária Catarinense. v. 7, p. 49-51, 1994.

ANVISA. Agência Nacional de Vigilância Sanitária. Disponível em: < http://portal.anvisa.gov.br/>. Acessado em: 14 de mio de 2019.

AOCS, 2004 - AMERICAN OIL CHEMISYS SOCIETY - AOCS - Official Methods and Recommended Practices of the American Oil Chemists Society. Washington, 2004. 2002.

BISOGNIN, D.A. Origin and evolution of cultivated cucurbits. Ciência Rural 32: 715 723,

HIGBY, W. K. A. A simplified method for determination of some the carotenoid distribution in natural and carotene fortified orange juice. Journal of Food Science, v. 27, p. 42-49, 1962.

MACHADO, G. C.; CHAVES, J.B.P.; ANTONIASSI, R. Composição em ácidos graxos e caracterização física e química de óleos hidrogenados de coco babaçu. Revista Ceres. 53 (308), 463, 2006.

MAIA, E.L. Material Didático Teórico - Tecnologia do Pescado I, Universidade Federal do Ceará, Fortaleza, 2006.

O'BRIEN, R. D. Fats and oils: formulating and processing for applications. London: Crc Press, 2004.

SINGLETON, V.L.; ORTHOFER, R.; LAMUELA-RAVENTOS, R.M.. Analysis of total phenols and other oxidation substrates and antioxidants by means of folin-ciocalteu reagent. Methods in enzymology, n. 299C, p. 152-178, 1999.

STROHECKER, R.; HENNING, H.M. Análises de vitaminas: métodos comprovados, Madrid: Paz Montolvo, 1967. 428 p.

VERONEZI, C.M.; JORGE, N. Aproveitamento de sementes de abóbora (Cucurbita sp) como fonte alimentar. Revista Brasileira de Produtos Agroindustriais, Campina Grande, v.14, n.1, p.113-124, 2012. 